\title{
Shelf Sequence and Proximity Effects on Online Grocery Choices
}

\author{
Els Breugelmans* \\ Maastricht University
}

Katia Campo

Catholic University of Leuven

Els Gijsbrechts

University of Tilburg

Published as: E. Breugelmans, K. Campo and E. Gijsbrechts (2007), "Shelf Sequence and Proximity Effects on Online Grocery Choices", Marketing Letters 18 (1-2), 117-133.

\section{Acknowledgments}

The authors acknowledge the financial support of the Fund for Scientific Research, Flanders (FWO-Vlaanderen). The authors are much indebted to the respondents who pretested the experimental design and those who participated in the research. They also thank Patrick De Pelsmacker, Gilles Laurent, Annouk Lievens, Patrick Van Kenhove, Walter van Waterschoot, and Philippe Verbeeck; two anonymous reviewers; and the editor for their helpful suggestions on previous versions of this article.

\footnotetext{
${ }^{*}$ Corresponding Author.

Els Breugelmans is Post-Doc Researcher at the Faculty of Economics and Business Administration, Department of Marketing, Maastricht University. Address: P.O. Box 616, 6200 MD Maastricht, The Netherlands. Tel. +31433883855; Fax +31-433884918. E-mail: e.breugelmans@mw.unimaas.nl

Katia Campo is Associate Professor of Marketing at the Faculty of Economics and Applied Economics, Department of Marketing and Strategy, Catholic University Leuven. Address: Naamsestraat 69, 3000 Leuven, Belgium. Tel. +32-16326819; Fax +32-16326732. E-mail : katia.campo@econ.kuleuven.be

Els Gijsbrechts is Professor of Marketing at the Faculty of Economics and Business Administration, Department of Marketing, University of Tilburg. Address: P.O. Box 90153, 5000 LE Tilburg, The Netherlands. Tel. +31134668224; Fax.+31-134668354. E-mail: E.Gijsbrechts@uvt.nl
} 


\section{Shelf Sequence and Proximity Effects on Online Grocery Choices Abstract}

Research on shelf effects in traditional grocery stores shows that a product's absolute and relative shelf position may strongly affect consumer choices. The authors examine whether and how such shelf effects translate to an online grocery context. We find that a product's choice probability increases when presented on the first screen or located near focal items, especially when the latter are out-of-stock. These primacy and proximity effects have stronger impacts on choice decisions when assortments are more difficult to evaluate and when a clear shelf organization facilitates the use of shelf-based choice heuristics.

Keywords: Retailing, Shelf management, Assortment, Online shopping, Choice decision

The Internet revolution has initiated a new era in which online shopping has become a wellaccepted way to purchase products. Previous research has examined the effects of unique online store characteristics, such as interactive decision aids and more flexible customization procedures (e.g., Senecal and Nantel 2004; Zhang and Krishnamurthi 2004), but less attention has been paid to the equally intriguing question of whether traditional marketing mix instruments affect online purchase decisions to the same extent and in the same manner. Various studies indicate that online shoppers may react differently to marketing mix instruments, such as price and brand name (e.g., Andrews and Currim 2004; Degeratu, Rangaswamy, and $\mathrm{Wu} 2000)$.

Because of the differences in store environments, an even stronger divergence may be expected in consumer responses to merchandising instruments, such as shelf display (Liang and Lai 2002). For example, unlike traditional stores, online stores typically allocate only one facing to each product and thereby eliminate shelf space allocation effects. Furthermore, small and easily examinable electronic shelves greatly facilitate search processes. Limited eye movements and simple scrolling across screens enable consumers to scan the entire 
assortment, which may make shelf position less effective for drawing customer attention to specific products. Some authors even conclude that shelf management, though still a dominant concern in traditional retail settings, is irrelevant in virtual stores (e.g., Menon and Kahn 2002; Yrjölä 2001). Our study suggests that online shelf display may affect consumers' shopping decisions in its own way, because the order in which products are displayed and their position relative to other items continue to play important roles in directing customer attention and guiding online choice decisions.

Systematic analyses of online shelf effects have been lacking prior to now. This research offers a first step in closing this gap. We examine whether traditional shelf effects prevail for online choices and, if so, how they translate to a virtual store context. In line with previous merchandising studies, we focus on shelf effects for fast-moving consumer goods (FMCGs), for which consumers often rely on simplified choice heuristics. Based on an online shopping experiment, we also provide indications about the drivers and magnitude of online shelf effects and suggest guidelines for improved shelf management. In the following section, we briefly review traditional shelf literature and develop hypotheses about online shelf effects. Next, we describe the experiment and model we use to test these effects. We then discuss implications for virtual shelf management and indicate directions for further research.

\section{Traditional and online shelf effects}

\subsection{Traditional shelf effects}

The impact of shelf display on consumers' choice decisions in brick-and-mortar grocery stores has been widely supported. Items are more likely to be chosen when they receive more shelf space (more facings) or are placed on more prominent shelf positions (Desmet and Renaudin 1998; Drèze, Hoch, and Purk 1994). In terms of absolute shelf placement, vertical shelf position appears to have the strongest effect: products placed at eye or hand level have a 
significantly higher probability of being selected (Campo and Gijsbrechts 2005; Corstjens and Corstjens 1995). The impact of horizontal shelf position appears less pronounced, and early results were inconclusive regarding which position is best (Drèze et al. 1994). However, recent research suggests that much depends on the entrance point of the shelf: in line with the primacy effect observed in communication literature, items encountered earlier appear more likely to be chosen (Broere, Van Gensink, and Van Oostrom 1999). Moreover, a product's relative shelf position may affect its choice probability, such that a placement near focal (i.e., highly preferred) items increases the probability that consumers will notice and select the product (Simonson and Winer 1992).

These shelf effects appear especially important when consumers are not highly involved with the purchase decision, are pressed for time, and/or face comprehensive shopping tasks. In such situations, consumers often pursue satisfactory rather than utility-maximizing purchase decisions (Hoyer 1984). Therefore, shelf display may play an important role in attracting customer attention and serve as a cue that simplifies consumers' choice decisions.

Products with more facings or that are placed on more prominent shelf positions are more likely to be noticed or catch consumers' attention first. The sequence of attention becomes especially important when consumers seek a satisficing, effortless solution, because they tend to conclude their search process as soon as they find a suitable product (Simonson 1999). Even when they continue their search process, they pay less attention to products they encounter in a later stage, apparently because they have settled on a specific product and merely scan subsequent items to justify their choice. The probability that an item will be chosen thus depends on where consumers start their search: the shelf area that first catches their attention (as triggered by the number of facings, point of shelf entrance, or vertical shelf position) or the area that contains the most salient (i.e., preferred) item. In addition to these 
attention-steering effects, shelf display may provide cues of product attractiveness, because more popular items often receive more shelf space and/or more prominent shelf positions.

\subsection{Online shelf effects}

The key question for this research is whether and how traditional shelf effects translate to online settings. Because of the differences between virtual and physical store shelves, we expect shelf space and vertical shelf position (eye level) to play no or a minor role in online settings. First, unlike traditional stores, online stores typically allocate only one facing to each item, which makes the number of facings a non-issue. Second, because all products are placed essentially at eye level when displayed on a small computer screen, vertical shelf position may no longer drive customer attention. Results from communication literature seem to confirm these claims; advertisements in comparable (i.e., small, two-dimensional) media do not attract substantially more attention when they appear in specific, on-page positions (Hanssens and Weitz 1980). In media used for product selections, such as catalogs and store flyers (Nagelkerke 2004) that provide quick and easy overviews, consumers use many different starting points and scanning procedures (e.g., Monk 1984).

In contrast, we expect that sequence effects, which are triggered in traditional stores by horizontal shelf positions, will remain relevant in virtual stores. Because of the absence of physical space constraints, online assortments are often quite large and require more than one screen to display all items. In addition, though browsing online shelves entails less effort than searching physical store shelves, online customers are not oblivious to search costs. Typically convenience oriented, online shoppers may be equally reluctant to engage in a complete category search, even if they only have to scroll among different screens (Kumar, Smith, and Bannerjee 2004; Wu and Rangaswamy 2003). In line with traditional store shelf literature, we expect that products encountered earlier during the search process will receive more attention 
(primacy effect) and hence have a higher probability of being chosen. However, in contrast with traditional stores, online stores have a fixed entrance point. So we expect that, just as cover page positions enhance ad visibility (Gijsbrechts, Campo, and Goossens 2003), placement on the first screen will entail substantially higher customer attention and choice probabilities.

$H_{1}$ (Shelf sequence effect): Items displayed on the first screen of an online store have a higher probability of being chosen.

Previous research also indicates that once consumers have fixed their attention on a part of the shelf, they continue to focus on the subset of items displayed in that particular shelf section (for traditional settings, see Hoch, Bradlow, and Wansink 1999; Simonson and Winer 1992; for online contexts, see Hong, Thong, and Tam 2004-5). Such search behavior may be driven by a desire to simplify the choice process and the perception that more closely positioned items are more similar (Morales et al. 2005). We therefore expect that online shoppers will confine their search to the shelf section that contains their focal item.

$\mathrm{H}_{2}$ (Proximity effect): Items located next to a consumer's focal item have a higher probability of being chosen.

These shelf sequence $\left(\mathrm{H}_{1}\right)$ and proximity $\left(\mathrm{H}_{2}\right)$ effects result directly from consumers' pursuit of satisficing and effortless solutions, which trigger the need to simplify choice heuristics. As we indicated previously, consumer recourse to such heuristics becomes more likely for complicated (but low-involvement) shopping tasks. Previous research also suggests that assortments are more difficult to evaluate when they comprise more items (assortment size; Broniarczyk, Hoyer, and McAlister 1998) and/or the items are displayed in a disorganized way (assortment structure; Drèze et al. 1994; Hoch et al. 1999).

$\mathrm{H}_{1 \mathrm{a}}$ : A first-screen shelf position has a stronger positive effect on an item's choice probability when the product assortment is larger. 
$\mathrm{H}_{2 \mathrm{a}}$ : Proximity to focal items has a stronger positive effect on an item's choice probability when the product assortment is larger.

$H_{1 b}$ : A first-screen shelf position has a stronger positive effect on an item's choice probability when products are displayed in a disorganized way.

$H_{2 b}$ : Proximity to focal items has a stronger positive effect on an item's choice probability when products are displayed in a disorganized way.

\section{Methodology}

\subsection{Experimental data}

We collected data through a realistic online store experiment, which enables us to manipulate the treatment variables, such as shelf display and assortment, while controlling for extraneous influences, such as store promotions (Campo and Gijsbrechts 2005). Growing evidence indicates that computer-simulated shopping experiments provide highly realistic buying behavior data, especially when the decision cues mimic those of a real store environment (Burke et al. 1992; Campo, Gijsbrechts, and Guerra 1999). This is particularly applicable to our study, in which we use the site of an existing e-grocery store as a starting point. ${ }^{1}$ We also use scanned pictures of actual products to facilitate visual product recognition and include the capacity for respondents to retrieve additional product information.

The computer experiment consists of (1) a prepurchase questionnaire to collect consumer background data, (2) a purchase simulation module, and (3) a postpurchase questionnaire pertaining to the decision-making process and virtual store experiences. Respondents made hypothetical online purchases during six weeks ${ }^{2}$ for two product categories (margarine and cereals). To enhance the realism of their purchase decisions, we informed consumers of their home inventory levels (computed on the basis of previous 
purchases and reported consumption rates) and explicitly told them they were not obliged to buy during every (fictitious) shopping trip.

In addition, similar to real online shopping environments, our virtual store exhibits stock-outs at a realistic average rate of $8 \%$ of the products in the category (Sloot, Verhoef, and Franses 2005). We uniformly distribute the stock-out occurrence across weeks, low and high share items, and attribute levels (brands, flavors, size). The out-of-stock products remain visible on the screen with a flag signaling their unavailability. In addition to enhancing realism, these stock-out occurrences offer a more in-depth exploration of proximity effects as explained below.

We manipulate absolute and relative shelf position through changes in the shelf arrangement according to brand or flavor/type (in practice, the most commonly used arrangements). Consumers were assigned randomly to one of either arrangement. Depending on the shelf arrangement, the on-screen positions, order of appearance, and product adjacencies differ. In addition, we expect that the type of shelf arrangement will influence shelf organization perceptions.

For our assortment size manipulations, we follow retailer practices and make brand and flavor the predominant attributes along which the assortments could be extended (Boatwright and Nunes 2001). Subjects were assigned randomly to one of three different assortments: (1) a limited assortment, (2) an assortment extended by flavors, and (3) an assortment extended by brands. In Table 1, we provide an overview of each category and assortment of the number of products, respondents, and purchase occasions.

$$
<\text { insert Table } 1>
$$

To get a representative sample, we use e-mail addresses obtained from a list broker (addresses selected on the basis of demographic and purchase behavior information) and the full staff of a university (including technical and administrative staff). For each address, we 
requested the participation of the household member typically in charge of grocery shopping. ${ }^{3}$ Of these potential households, $17 \%$ completed the purchase simulation, a response rate that compares favorably to other online surveys (e.g., Verhoef and Langerak 2001). In addition, the sociodemographic characteristics of our sample match online grocery sample profiles in other studies (e.g., Degeratu et al. 2000; Rohm and Swaminathan 2004).

\subsection{Model structure}

To test the hypotheses, we introduce shelf placement variables in a traditional multinomial logit (MNL) model. Specifically, our choice utilities take the following form:

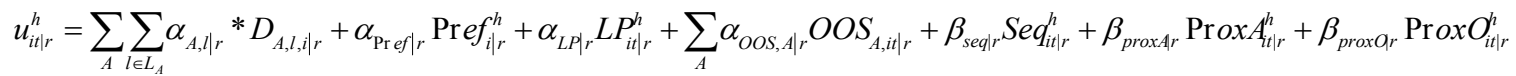

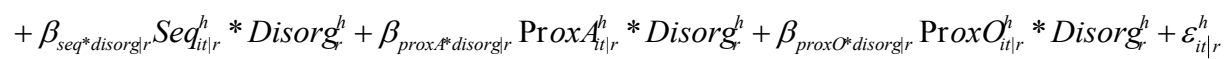

where $u_{\mathrm{it|r}}^{\mathrm{h}}$ is the choice utility of item $\mathrm{i}$ for household $\mathrm{h}$ facing assortment $\mathrm{r}$ at time $\mathrm{t}$, and $\varepsilon_{\mathrm{it|r}}^{\mathrm{h}}$ is the random (extreme value distributed) error component.

The first set of variables consists of traditional household/item variables, such as attribute-specific intercept terms ${ }^{4}\left(D_{A, l, i}\right)$, long-term preference measures $\left(\operatorname{Pref}_{i}^{h}\right)$, purchase event feedback variables $\left(L P_{i t}^{h}\right)$, and attribute-specific stock-out asymmetry variables $\left(O O S_{A, i t}\right)$ (see Table 2). The latter capture possible non-IIA choice shifts triggered by stockouts (Campo, Gijsbrechts, and Nisol 2003). A positive (negative) coefficient indicates a tendency to switch to (away from) items that have the same attribute as the stock-out item.

<insert Table 2>

The sequence variable $(S e q)$ is a dummy variable that indicates whether item $\mathrm{i}$ is displayed on the first screen, which should enhance the item's choice probability $\left(\mathrm{H}_{1}: \beta_{\text {seq }}>0\right)$. We capture relative shelf placement effects by the proximity variables (ProxA, ProxO), which determine whether an item is positioned next to the respondent's focal item(s). We identify those focal items from the postpurchase questionnaire on the basis of long-term item 
preference. If a respondent marks several items as focal (i.e., Pref $>0$ ), the items receive weights according to reported preference shares (see Table 2). According to $\mathrm{H}_{2}$, adjacency to focal products enhances attention and increases choice probability $\left(\mathrm{H}_{2}: \beta_{\text {prox }}>0\right)$. Although such proximity effects may occur when the focal item is available, we expect them to be particularly pronounced when the focal item is out-of-stock, which forces consumers to adjust their choices. To explore this phenomenon, we introduce two separate proximity variables: ProxA (focal item is adjacent to product $\mathrm{i}$ and available) and ProxO (focal item is adjacent to product $\mathrm{i}$ and out-of-stock) and expect $\beta_{\text {proxo }}>\beta_{\text {proxA }}$.

The last three terms of equation (1) capture the interaction effects between sequence/proximity variables and perceived degree of shelf organization (as reported in the postpurchase questionnaire)..$^{5}$ As we indicate in $\mathrm{H}_{1 \mathrm{~b}}$ and $\mathrm{H}_{2} \mathrm{~b}$, we expect disorganized displays to stimulate the use of shelf-based, simplified choice heuristics. To test the moderating effect of assortment size $\left(\mathrm{H}_{1 \mathrm{a}}\right.$ and $\left.\mathrm{H}_{2 \mathrm{a}}\right)$, we allow the parameters of the shelf-based variables to vary across assortments.

\subsection{Estimation}

In each category, we estimate the choice model across the three assortments:

$$
p_{i t \mid r}^{h}=\frac{\exp \left[\mu_{r}\left(u_{i t \mid r}^{h}\right)\right]}{\sum_{j \in C_{t \mid a}^{h}} \exp \left[\mu_{r}\left(u_{j t \mid r}^{h}\right)\right]} \text { for } i \in C_{t \mid r}^{h},
$$

where $p_{i t \mid r}^{h}$ is the probability that household $\mathrm{h}$ chooses item $\mathrm{i}$ facing assortment $\mathrm{r}$ at time $\mathrm{t}$, $\mathrm{u}_{\mathrm{it|r}}^{\mathrm{h}}$ is the choice utility of item $\mathrm{i}$ for household $\mathrm{h}$ facing assortment $\mathrm{r}$ at time $\mathrm{t}, C_{t \mid r}^{h}$ is the set of category items available to household $\mathrm{h}$ within assortment $\mathrm{r}$ at time $\mathrm{t}$, and $\mu_{r}$ is the Gumbel scale factor.

As recommended by Swait and Andrews (2003), we allow the scale factors $\mu_{r}$ and key utility parameters (including shelf effects) to differ among assortments. ${ }^{6}$ For identification purposes, we normalize the scale factor of the first (limited) assortment to $1\left(\mu_{1}=1\right)$ (cf. 
Andrews and Currim 2002; Swait and Louvière 1993). To accommodate household heterogeneity, we opt for a continuous mixture approach with normally distributed parameters across households (McFadden and Train 2000). As suggested by Train (2001), we do not introduce random effects for attribute-specific constants ${ }^{7}$ or for variables that already capture preference heterogeneity, such as the long-term preference measure and proximity variables. We estimate the mixed MNL (MMNL) model through simulated maximum likelihood using the quasi-random Monte Carlo (or Halton) method (Bhat 2001).

\section{Estimation results}

In Table 3, we present, per category, the estimation results for models with main shelf sequence and proximity effects (Panel a) and interaction effects added between shelf sequence/proximity and perceived degree of shelf organization (Panel b). For both models and categories, the coefficients of the non-shelf-related variables (attribute constants, longterm item preference, last purchase, stock-out asymmetry) are significant in the majority of cases with the expected sign. In the remainder of this section, we discuss the main effects of shelf sequence/proximity variables and then indicate how these effects depend on assortment size and the perceived degree of shelf organization.

$$
<\text { insert Table } 3>
$$

\subsection{Main shelf effects}

As we show in Panel a of Table 3, the sequence variable has a positive and significant impact in assortment 2 for margarine $\left(\beta_{\text {seq } \mid 2}=.43, \mathrm{p}<.05\right)$ and in assortment 3 for cereals $\left(\beta_{\text {seq } \mid 3}=.47\right.$, $\mathrm{p}<.05$ ). In both categories, we find evidence of a primacy effect, in support of $\mathrm{H}_{1}$. Note that for margarine in assortment 1, all items are visible on one screen, which eliminates any possible first-screen effects. However, in the assortments in which this parameter is 
significant, first-screen alternatives experience an important increase in choice probability, averaging 13.39\% for margarine (assortment 2) and 16.08\% for cereals (assortment 3).

We observe a similar pattern for the proximity effects. Being adjacent to a focal product significantly increases an item's choice probability in assortment 2 for margarine $\left(\beta_{\text {proxo } \mid 2}=1.06, \mathrm{p}<.01 ; \beta_{\text {prox } A \mid 2}=.86, \mathrm{p}<.01\right)$ and in assortment 3 for cereals $\left(\beta_{\text {proxO } \mid 3}=3.80\right.$, $\left.\mathrm{p}<.01 ; \beta_{\text {prox } A \mid 3}=1.72, \mathrm{p}<.01\right)$. Thus, consumers tend to fix their attention on the shelf area that contains their focal item and are more likely to select a proximate rather than a distant item, in support of $\mathrm{H}_{2}$. In addition, the proximity effect grows much stronger when the focal item is unavailable $\left(\beta_{\text {proxo }}>\beta_{\text {proxA }}\right.$ ). The results for assortments 1 and 2 for cereals point in the same direction; a position near focal items increases a product's choice probability only when the focal items are out-of-stock $\left(\beta_{\text {proxo } \mid 1}=1.98, \mathrm{p}<.01 ; \beta_{\text {proxo } 2}=.35, \mathrm{p}<.01\right)$. When significant, the proximity effects are substantial, and items close to the unavailable (available) focal items enjoy, on average, 9.86\% (8.51\%) (margarine, assortment 2); 21.70\% (n.s.) (cereals, assortment 1); 7.84\% (n.s.) (cereals, assortment 2); and 41.70\% (18.90\%) (cereals, assortment 3) higher propensities of being selected.

\subsection{Moderating effect of assortment size}

These results already demonstrate that sequence and proximity effects vary across assortments. However, we find support for our expectation that larger assortments are more difficult to evaluate, and therefore stimulate shelf-based choice heuristics $\left(\mathrm{H}_{1 \mathrm{a}}\right.$ and $\left.\mathrm{H}_{2 \mathrm{a}}\right)$, only for one of the large assortments (assortment 2 for margarine, assortment 3 for cereals). ANOVAs of assortment differences in the ease-of-processing scores ${ }^{8}$ (captured in the postpurchase questionnaire) clarify what drives these results. As we indicate in Table 4, significant shelf effects prevail in more difficult-to-evaluate assortments, which is in line with the intuition behind $\mathrm{H}_{1 \mathrm{a}}$ and $\mathrm{H}_{2 \mathrm{a}}$ that shelf-based heuristics are used more often in complex 
choice situations. However, consumers' ease of processing is not driven by assortment size but rather by composition, such that assortments extended along the most important product attribute (brand for margarine, flavor for cereals ${ }^{9}$ ) facilitate the selection process (Boatwright and Nunes 2001) and reduce the need to rely on simplifying, shelf-based choice heuristics.

$$
<\text { insert Table } 4>
$$

\subsection{Interaction effect of perceived shelf organization}

According to Panel b of Table 3 and Jaccard, Turrisi, and Wan's (1990) test of interaction effects, sequence and proximity effects are significant only at low levels of perceived shelf organization. So, in contrast to $\mathrm{H}_{1 b}$ and $\mathrm{H}_{2 b}$, we find that sequence and proximity affect customer choices more strongly when the shelf is perceived as well-organized. This surprising result may be explained in two ways. First, manipulation checks indicate that despite the sufficient variation in the perceived degree of shelf organization, few consumers appear to consider the shelf really disorganized (variable heavily skewed toward organized ${ }^{10}$ ). This may be because the shelf is always organized along main product attributes (i.e., brand or flavor). Second, more clearly structured shelves may increase consumers' confidence of attaining an acceptable outcome from shelf-based choice heuristics and facilitate holistic information processing (Hoch et al. 1999). Therefore, consumers might scan the shelf first to locate subsections that contain the most interesting items and then make a final choice from the limited set of items within these subsections (Hong et al. 2004-5; Morales et al. 2005).

\subsection{Robustness checks}

To verify the validity of our findings, we conduct several robustness checks. First, we test alternative operationalizations of the sequence effect. Replacing the first-screen definition with a count variable (which reflects the serial order in which consumers encounter products when they scroll to subsequent screens) does not produce any improvement in model fit. We 
also add a last-screen variable, which has a negative effect and thereby confirms that primacy effects are more important than recency effects. Second, in addition to the sequence variable, we insert an on-shelf position variable to capture the placement of the products on the first screen. We test several alternatives and determine whether items presented on (1) top rows, (2) middle rows (the counterpart of eye/hand level), or (3) top-left positions have higher choice propensities. As we expected, none of these alternative on-screen variables improve model fit or face validity. Third, to ensure that our proximity and sequence effects are not an artifact of the shelf arrangement (i.e., by brand or flavor), we test a model that includes interaction effects between attribute-specific constants and/or attribute stock-out asymmetry on the one hand and shelf arrangement on the other hand. We also test interactions between the sequence/proximity variables and shelf arrangement. Most of these adjustments indicate insignificance, and in no cases does the model fit improve. ${ }^{11}$ Therefore, our sequence and proximity variables reflect primacy and product adjacency effects, not brand or variety preferences.

\section{Discussion}

Despite the ongoing debates about the ease of searching on the Internet, shelf management remains an important issue for online grocery stores. First, we find that across-screen placements may affect choices. First-screen alternatives are more likely to be selected, because consumers start to acquire and process information on that screen and, for FMCGs, search for a satisficing rather than an optimizing solution (primacy effect). The fight for shelf space thus becomes a fight for first-screen placement, and retailers and manufacturers should attempt to procure positions on the initial category screen to highlight specific (e.g. highermargin, private label) items they want to push. Although many e-grocery sites offer users the ability to change the shelf layout, consumers see the default/start option first, and similar to 
previous research (Wu and Rangaswamy 2003), our results show that they tend to stay with this option.

Second, even though the absolute placement of products on a screen is not influential, their placement relative to other items is. When consumers focus on a particular shelf section, they stay within that section. Especially when the focal item is out-of-stock, closely positioned alternatives experience a strong positive effect on their choice probabilities. Even when the favored product is available, we find that other items significantly benefit from being placed adjacent to it.

Third, though their potential impact is substantial, sequence and proximity effects are not always active. Our study clearly highlights some conditions in which shelf effects prevail. We find that consumers are more inclined to adopt shelf-based heuristics when they experience more difficulty in finding and choosing an item among an assortment. The unavailability of key product attributes, rather than assortment size, serves to complicate decision processes, which is consistent with Boatwright and Nunes's (2001) findings. Also, rather than making shelf-based heuristics redundant, a transparent shelf structure increases consumers' confidence in outcomes and thus stimulates their use.

Our research contains several limitations. First, using an experiment may have created biases due to the absence of budget/time constraints or the relatively easy shopping task. Our test thus may be a conservative one, in that consumers probably use heuristics more often when they have a long shopping list and/or are really pressed for time. Also, the limited number of shopping occasions in our study make it difficult to account for dynamic elements, such as store familiarity. Real-time longitudinal studies could shed more light on the use of shelf-based cues over time.

Second, we manipulate only two possible assortment extensions and consider modestly sized assortments. That we find evidence of shelf-based heuristics in such a setting is 
encouraging, but more extensive analysis is needed to determine whether and how assortment differences (e.g., more assortment size/composition variations) in a broader range of categories affect perceived decision difficulty and the use of shelf-based heuristics.

Third, our results apply to grocery e-tailers, for which consumers typically have directed search goals, not necessarily to all online e-tailers. Investigating the impact of shelf-based heuristics in other environments that involve different shopping goals (e.g., browsing; Hong et al. 2004-5) could offer a useful extension.

Fourth, though our experiment provides interesting findings, it also raises several new issues. The absence of significant on-screen effects may be a result of brand stimulus characteristics for which we fail to control (e.g., package color; van der Lans, Pieters, and Wedel 2005) and that may dominate on-screen salience or blur consumers' systematic search patterns. Experimental approaches that allow for closer analyses of consumers' decision processes (e.g., decision time, eye movements) may shed more light on these interesting issues. Such analyses also could provide better insights into the reasons that underlie the primacy effect: Does it rely on a narrowing of the consideration set or a reduction in the degree of consideration? In addition, it would be worthwhile to explore what determines shelf (dis-)organization perceptions, which in our study do not relate to the type of shelf arrangement or congruency between the shelf arrangement and consumers' dominant choice criteria.

Fifth, the finding that online grocery shoppers are susceptible to shelf placement effects opens exciting new research possibilities regarding the influence of typical online instruments, including display customization, cross-merchandising, and the availability of previous shopping lists. 


\section{Notes}

${ }^{1}$ The software and experimental site were developed by Hypervision, the software company responsible for the e-grocery site. Some adjustments were made to fit our experimental design (e.g., absence of promotions).

2 Previous research demonstrates that the time compression of several fictitious shopping trips into one experimental session does not preclude realistic dynamic purchase patterns (Burke et al. 1992).

3 To stimulate participation without endangering the representativeness of the sample, we made participants eligible for small rewards on a lottery basis. The probability of receiving the reward was not linked to task performance but used only to enhance response rates. The reward was sufficiently small to avoid any effects on sample composition or simulated purchase behavior. In line with previous computer-simulated shopping experiments (e.g., Burke et al. 1999; Campo et al. 1999), we stimulate respondents to imitate their normal buying behavior by providing clear task instructions and realistic decision cues (see Section 2.1).

${ }^{4}$ Traditionally, price would be included in the utility function. However, in our experimental setup, prices do not change over time and therefore are strongly linked to the set of attributes that describes the stock keeping unit (SKU). Estimation of a model incorporating both SKU attribute constants and price would lead to serious estimation problems because of the collinearity between the sets of variables.

${ }^{5}$ We test two alternative measures of shelf organization: (1) type of shelf arrangement (by brand or by flavor) and (2) congruency (Morales et al. 2005), which indicates whether shelves are arranged according to the consumer's dominant choice criterion (derived from the postpurchase questionnaire). In neither case does the introduction of the interaction terms provide a significant improvement in model fit. Further analysis reveals that, contrary to our expectations, the perceived degree of shelf organization is weakly related to more objective measures, such as the type of shelf arrangement or the degree of (shelf-choice) congruency. In line with previous studies (e.g., Drèze et al. 1994), this finding points to the need for further research on the underlying factors of shelf organization perceptions.

${ }^{6}$ As we argue previously, consumers are more likely to turn to task-simplifying tactics when they must search for a (replacement) product in a large compared with a small assortment. We expect differences with respect to the sequence, proximity, and asymmetric switching variables among assortments, with more significant effects in large than in small assortments $\left(\mathrm{H}_{1 \mathrm{a}}\right.$ and $\left.\mathrm{H}_{2 \mathrm{a}}\right)$. Although we do not explicitly include hypotheses with respect to the moderating effect of assortment size on the tendency to switch asymmetrically to items with specific attributes, a similar logic may hold for such asymmetry variables. The probability that consumers will focus on key product attributes as a heuristic to make easy and effortless decisions is more likely in a large than in a small assortment. Composition also might affect the tendency to use specific asymmetric switching heuristics. Therefore, we do not constrain asymmetric switching variables to be equal across assortments. In contrast, the long-term item preference tendency or the tendency to repurchase the same item is a personality trait that likely is prevalent across assortments (cf. Andrews and Currim 2002). We confirm the validity of these choices with robustness checks that explicitly test whether variables should be pooled.

${ }^{7}$ We decide for various reasons to keep the attribute-specific coefficients constant. First, mixed logit models have a tendency to be unstable when all coefficients are allowed to vary (Train 1999). Models in which all coefficients vary, do not converge in any reasonable number of iterations. Fixing the attribute-specific coefficients resolves this instability. Second, Train (2001) indicates that the mixture might be empirically unidentifiable in a model in which, next to final iid extreme-value terms, the item-specific dummy coefficients are assumed to be random. Including a similar distribution (as is the case for the normal and extreme value distribution) results in unstable estimations, because the final iid extreme-value terms in a model with itemspecific constants already constitute the random portion of these constants. Robustness checks that explicitly test whether variables should be fixed confirm the validity of our choices.

${ }^{8}$ Ease of processing has a Cronbach's alpha of .814 (.875) for margarine (cereals). We confirm the factor structure through principal components analysis.

${ }^{9}$ In line with previous results, we find that the type of attribute guiding customer choices differs between categories (e.g., Campo et al. 2003). In the cereals category, $70 \%$ of the respondents indicated in the postpurchase questionnaire that they place strong emphasis on flavor, whereas only $44 \%$ of shoppers mention this criterion for selecting margarine. Margarine choices, in contrast, are strongly guided by brand cues: $49 \%$ of margarine buyers mention it as important, whereas only $17 \%$ do so for cereals.

${ }^{10}$ Reestimating the model with a transformation of the perceived shelf organization variable to achieve normality does not change the results.

${ }^{11}$ The stock-out asymmetry variables already recognize that, when facing stock-outs, consumers may switch more readily to items of the same size, brand, and/or flavor. Proximity effects thus reflect the impact of product adjacencies over and above attribute-driven switches. The robustness checks provide an additional guarantee that it is proximity, not attribute-based shelf arrangement that drives the results. 


\section{References}

Andrews, R.L. and I.S. Currim. (2002). "Identifying Segments with Identical Choice Behaviors Across Product Categories: An Intercategory Logit Mixture Model”. International Journal of Research in Marketing 19 (1), $65-$ 79.

Andrews, R.L. and I.S. Currim. (2004). "Behavioral Differences Between Consumers Attracted to Shopping Online versus Traditional Supermarkets: Implications for Enterprise Design and Marketing Strategy". International Journal of Internet Marketing and Advertising 1 (1), 38-61.

Bhat, C.R. (2001). “Quasi-Random Maximum Simulated Likelihood Estimation of the Mixed Multinomial Logit Model”. Transportation Research 35B (7), 677-695.

Boatwright, P. and J.C. Nunes. (2001). "Reducing Assortment: An Attribute-Based Approach". Journal of Marketing 65 (3), 50-63.

Broniarczyk, S.M., Wayne D. Hoyer, and Leigh McAlister. (1998). “Consumers' Perceptions of the Assortment Offered in a Grocery Category: The Impact of Item Reduction”. Journal of Marketing Research 35 (2), $166-167$.

Broere, Van Gensink, and Van Oostrom. (1999). "De relatie tussen looprichting en aankoopgedrag". Erasmus Food Management Institute, EFMI 2001-05 (in Dutch).

Burke, R.R., B.A. Harlam, B. Kahn, and L.M. Lodish. (1992). "Comparing Dynamic Consumer Choice in Real and Computer-Simulated Environments”. Journal of Consumer Research 19 (1), 71 -82.

Campo, K. and E.Gijsbrechts. (2005). "Retail Assortment, Shelf and Stockout Management: Issues, Interplay and Future Challenges". Applied Stochastic Models in Business and Industry, 21 (3), 383-392.

Campo, K., E. Gijsbrechts, and F. Guerra. (1999). “Computer Simulated Shopping Experiments for Analyzing Dynamic Purchasing Patterns: Validation and Guidelines". Journal of Empirical Generalisations in Marketing Science 4, 22-61.

Campo, K., E. Gijsbrechts, and P. Nisol. (2003). "The Impact of Retailer Stockouts on Whether, How Much and What to Buy". International Journal of Research in Marketing 20 (3), 273-286.

Corstjens, J. and M. Corstjens. (1995). Store wars: The Battle for Mindspace and Shelfspace. Chichester: Wiley.

Degeratu, A.M., A. Rangaswamy, and J. Wu. (2000). "Consumer Choice Behavior in Online and Traditional Supermarkets: The Effects of Brand Name, Price, and Other Search Attributes”. International Journal of Research in Marketing 17 (1), 55-78.

Desmet, P. and V. Renaudin. (1998). "Estimation of Product Category Sales Responsiveness to Allocated Shelf Space". International Journal of Research in Marketing 15 (5), 443-457.

Drèze, X., S.J. Hoch, and M.E. Purk. (1994). "Shelf Management and Space Elasticity". Journal of Retailing 70 (4), 301-326.

Gijsbrechts, E., K. Campo, and T. Goossens. (2003). "The Impact of Store Flyers on Store Sales and Store Traffic: A Geomarketing Approach". Journal of Retailing 79 (1), 1-16.

Hanssens, D.M. and B.A. Weitz. (1980). "The Effectiveness of Industrial Print Advertisements across Product Categories". Journal of Marketing Research 17 (2) 294-306.

Hoch, S.J., E.T. Bradlow, and B. Wansink. (1999). "The Variety of an Assortment”. Marketing Science 18 (4), 527-577.

Hong, W., J.Y.L. Thong, and K.Y. Tam. (2004/5). "The Effects of Information Format and Shopping Task on Consumers' Online Shopping Behavior: A Cognitive Fit Perspective". Journal of Management Information Systems 21 (3), 149-184.

Hoyer, W.D. (1984). “An Examination of Consumer Decision Making for a Common, Repeat-Purchase Product”. Journal of Consumer Research 11 (3), 822-829.

Jaccard, J., R. Turrisi, and C.K. Wan. (1990). Interaction Effects in Multiple Regression. Newbury Park, CA: Sage. 
Kumar, R.L., M.A. Smith, and S. Bannerjee. (2004). "User Interface Features Influencing Overall Ease of Use and Personalization". Information \& Management 41 (3), 289-302.

Liang, T.-P. and H.-J. Lai. (2002). "Effect of Store Design on Consumer Purchases: An Empirical Study of OnLine Bookstores. Information \& Management 39 (6), 431-444.

McFadden, D. and K.E. Train. (2000). "Mixed MNL Models for Discrete Response”. Journal of Applied Econometrics 15 (5), 447-470.

Menon, S. and B.E. Kahn. (2002). "Cross-Category Effects of Induced Arousal and Pleasure on the Internet Shopping Experience". Journal of Retailing 78 (1), 31-40.

Monk, T. (1984). "Search". In J.S. Warm (ed.), Sustained Attention in Human Performance. New York: Wiley, 293-321.

Morales, D., B.E. Kahn, L. McAlister, and S.M. Broniarczyk. (2005). "Perceptions of Assortment Variety: The Effects of Congruency between Consumers' Internal and Retailers' External Organization”. Journal of Retailing 81 (2), 159-169.

Nagelkerke, J. (2004). "Towards Fair Manufacturer Fees: Measuring the Effectiveness of Store Flyer Advertisement Layout Using Panel Data”, unpublished dissertation, Tilburg University.

Rohm, A.J. and V. Swaminathan. (2004). "A Typology of Online Shoppers Based on Shopping Motivations". Journal of Business Research 57 (7), 748-757.

Senecal, S. and J. Nantel. (2004). "The Influence of Online Product Recommendations on Consumers' Online Choices". Journal of Retailing 80 (2), 159-169.

Simonson, I. (1999). "The Effect of Product Assortment on Buyer Preferences". Journal of Retailing 75 (3), 347-370.

Simonson, I. and R.S. Winer. (1992). "The Influence of Purchase Quantity and Display Format on Consumer Preference for Variety". Journal of Consumer Research 19 (1), 133-138.

Sloot, L.M., P.C. Verhoef, and P.H. Franses. (2005). "The Impact of Brand Equity and the Hedonic Level of a Product on Consumer Stock Out Reactions". Journal of Retailing 81 (1), 14-35.

Swait, J. and R.L. Andrews. (2003). "Enriching Scanner Panel Models with Choice Experiments". Marketing Science 22 (4), 442-460.

Swait, J. and J. Louvière. (1993). "The Role of the Scale Parameter in the Estimation and Comparison of Multinomial Logit Models". Journal of Marketing Research 30 (3), 305-315.

Train, K.E. (1999). "Halton Sequences for Mixed Logit". Working paper, University of California at Berkeley.

Train, K.E. (2001). "A Comparison of Hierarchical Bayes and Maximum Simulated Likelihood for Mixed Logit". Working paper, University of California at Berkeley

van der Lans, R., R. Pieters, and M. Wedel. (2005). "In Search of the Brand: A Conceptual Model and a First Empirical Study". Working paper, Tilburg University.

Verhoef, P. and F. Langerak. (2001). "Possible Determinants of Consumers' Adoption of Electronic Grocery Shopping in The Netherlands". Journal of Retailing and Consumer Services 8 (5), 275-285.

Wu, J. and A. Rangaswamy. (2003). "A Fuzzy Set Model of Search and Consideration with an Application to an Online Market”. Marketing Science 22 (3), 411-434.

Yrjölä, H. (2001). "Physical Distribution Considerations for Electronic Grocery Shopping". International Journal of Physical Distribution and Logistics Management 31 (10), 746-761.

Zhang, J. and L. Krishnamurthi. (2004). "Customizing Promotions in Online Stores". Marketing Science 23 (4), 561-578. 
Table 1: Descriptives for each assortment

\begin{tabular}{|c|c|c|c|c|c|c|}
\hline & \multicolumn{3}{|c|}{ MARGARINE } & \multicolumn{3}{|c|}{ CEREALS } \\
\hline Attribute & $\begin{array}{l}\text { Ass't 1 } \\
\text { (limited) }\end{array}$ & $\begin{array}{l}\text { Ass't } 2 \text { (add new } \\
\text { flavors of existing } \\
\text { brands) }\end{array}$ & $\begin{array}{l}\text { Ass't } 3 \text { (add } \\
\text { new brands of } \\
\text { existing flavors) } \\
\end{array}$ & $\begin{array}{l}\text { Ass't } 1 \\
\text { (limited) }\end{array}$ & $\begin{array}{l}\text { Ass't } 2 \text { (add new } \\
\text { flavors of existing } \\
\text { brands) }\end{array}$ & $\begin{array}{l}\text { Ass't } 3 \text { (add new } \\
\text { brands of existing } \\
\text { flavors) }\end{array}$ \\
\hline \multirow[t]{2}{*}{ Brand } & \multirow[t]{2}{*}{ Common $^{\mathrm{a}}$} & \multirow[t]{2}{*}{ Common } & Common & \multirow[t]{2}{*}{ Common } & \multirow[t]{2}{*}{ Common } & Common \\
\hline & & & Add new brands & & & Add new brands \\
\hline \multirow[t]{2}{*}{ Flavor } & \multirow[t]{2}{*}{ Common } & Common & \multirow[t]{2}{*}{ Common } & \multirow[t]{2}{*}{ Common } & Common & \multirow[t]{2}{*}{ Common } \\
\hline & & Add new flavors & & & Add new flavors & \\
\hline \# items & 11 & 19 & 17 & 21 & 32 & 46 \\
\hline \# resp & 105 & 116 & 100 & 81 & 97 & 87 \\
\hline $\begin{array}{l}\text { \# purchase } \\
\text { occasions }\end{array}$ & 275 & 279 & 278 & 271 & 261 & 281 \\
\hline
\end{tabular}

${ }^{\mathrm{a} C}$ Common refers to attribute levels present in all three assortments.

Table 2: Variables in MNL choice model

\begin{tabular}{|c|c|}
\hline Variable & Description \\
\hline $\bar{A}$ & Set of attributes relevant to the product category (e.g., brand, flavor, type, and/or package size) \\
\hline $\mathrm{L}_{\mathrm{A}}$ & ndex set of levels relevant for attribute A (e.g. brand $\mathrm{x}$, brand y) \\
\hline $\mathrm{D}_{\mathrm{A}, \mathrm{l}, \mathrm{i}}$ & $\begin{array}{l}\text { Attribute-level dummy variable (equal to } 1 \text { if item } \mathrm{i} \text { is characterized by level } 1 \text { on attribute } \mathrm{A} \text {, and } \\
0 \text { otherwise) }\end{array}$ \\
\hline $\operatorname{Pref}{ }_{i}^{h}$ & $\begin{array}{l}\text { Long-term preference of household } \mathrm{h} \text { for item } \mathrm{i} \text { measured as purchase share in the } 12 \text {-month } \\
\text { period prior to the experiment (as reported in the postpurchase questionnaire) }\end{array}$ \\
\hline$L P_{i t}^{h}$ & $\begin{array}{l}\text { Purchase event feedback dummy variable (equal to } 1 \text { when item } i \text { was last purchased by } \\
\text { household } h \text { at time } t \text {, and } 0 \text { otherwise) }\end{array}$ \\
\hline$O O S_{A, i t}$ & $\begin{array}{l}\text { oute A (equal to the number of alternatives similar to item } \\
\text { time } \mathrm{t} \text { ) }\end{array}$ \\
\hline $\operatorname{Seq}_{i t}^{h}$ & $\begin{array}{l}\text { Shelf sequence variable (equal to } 1 \text { if item } \mathrm{i} \text { for household } \mathrm{h} \text { is shown on the first screen at time } \mathrm{t} \text {, } \\
\text { and } 0 \text { otherwise) }\end{array}$ \\
\hline $\operatorname{Pr} o x O_{i t}^{h}$ & $\begin{array}{l}\text { Proximity variable based on preference for items that are unavailable during time } \mathrm{t} \text { (equal to the } \\
\text { weighted sum of the number of out-of-stock items }\left(j_{o o s}\right) \text { positioned next to item } \mathrm{i} \text { at time } \mathrm{t} \text { for } \\
\text { household h, with weights equal to the preference of household } \mathrm{h} \text { for the stock-out item } \\
\left.\left(\operatorname{Pref} j_{j_{o o s}}^{h}\right)\right) \\
\operatorname{Prox} O_{i t}^{h}=\sum_{j_{o o s}} \operatorname{Pref} f_{j_{o s s}}^{h} * A d j_{i-j_{o o s}, t}^{h} \\
\text { with } A d j_{i-j_{o o s}, t}^{h}=\text { adjacency dummy variable (equal to } 1 \text { if item } \mathrm{i} \text { is adjacent to stock-out item } \\
j_{\text {oos }} \text { for household h at time t, and } 0 \text { otherwise) }\end{array}$ \\
\hline $\operatorname{Pr} o x A_{i t}^{h}$ & $\begin{array}{l}\text { Proximity variable based on preference for items that are available during time } \mathrm{t} \text { (equal to the } \\
\text { weighted sum of the number of items } \mathrm{j} \text { positioned next to item } \mathrm{i} \text { at time } \mathrm{t} \text { for household } \mathrm{h} \text {, with } \\
\left.\text { weights equal to the preference of household } \mathrm{h} \text { for item } \mathrm{j}\left(\operatorname{Pr} e f_{j}^{h}, \mathrm{j} \neq j_{o o s}\right)\right) \\
\operatorname{Pr} o x A_{i t}^{h}=\sum_{j \neq j_{o o s}} \operatorname{Pr} e f_{j}^{h} * A d j_{i-j, t}^{h} \\
\text { with } A d j_{i-j, t}^{h}=\text { adjacency dummy variable (equal to } 1 \text { if item } \mathrm{i} \text { is adjacent to item } \mathrm{j} \text { for } \\
\text { household } \mathrm{h} \text { at time } \mathrm{t} \text {, and } 0 \text { otherwise) }\end{array}$ \\
\hline Dis & the postpurchase quest \\
\hline
\end{tabular}

Table 4: ANOVA-results for the impact of assortment

\begin{tabular}{|l|l|l|l|l|l|l|}
\hline Variable & \multicolumn{2}{|c|}{ Margarine } & \multicolumn{1}{c|}{ Cereals } \\
\cline { 2 - 6 } & $\begin{array}{c}\text { Ass't 1 } \\
\text { Limited }\end{array}$ & $\begin{array}{c}\text { Ass't 2 } \\
\text { Ext flavors }\end{array}$ & $\begin{array}{c}\text { Ass't 3 } \\
\text { Ext brands }\end{array}$ & $\begin{array}{c}\text { Ass't 1 } \\
\text { Limited }\end{array}$ & $\begin{array}{c}\text { Ass't 2 } \\
\text { Ext flavors }\end{array}$ & $\begin{array}{c}\text { Ass't 3 } \\
\text { Ext brands }\end{array}$ \\
\hline \# of items & 11 & 19 & 17 & 21 & 32 & 46 \\
\hline $\begin{array}{l}\text { Ease of } \\
\text { processing }\end{array}$ & 5.59 & 5.67 & $\mathbf{5 . 8 9}$ & 5.48 & $\mathbf{5 . 8 5}$ & 5.28 \\
\cline { 2 - 7 } & Significant difference: 1 \& $3,2 \& 3$ & Significant difference: 1 \& 2, 2 \& 3 \\
\hline
\end{tabular}


Table 3: Model estimation results ${ }^{\mathrm{a}}$

\begin{tabular}{|c|c|c|c|c|c|c|c|}
\hline \multicolumn{4}{|c|}{ Margarine } & \multicolumn{4}{|c|}{ Cereals } \\
\hline Variable & Assortment 1 & Assortment 2 & Assortment 3 & Variable & Assortment 1 & Assortment 2 & Assortment 3 \\
\hline \multicolumn{8}{|l|}{ PANEL A } \\
\hline Scale factor & {$[1.00]$} & $1.3319^{* * *}$ & $1.2861^{* * *}$ & Scale factor & {$[1.00]$} & $1.0877^{* * *}$ & $0.8136^{* * *}$ \\
\hline Mean & & & & Mean & & & \\
\hline Last purchase & $1.9938 * * *$ & {$\left[2.6555^{* * *}\right]^{\mathrm{b}}$} & {$[2.5642 * * *]^{\mathrm{b}}$} & Last purchase & $0.6377 * * *$ & {$\left[0.6936^{* * *}\right]^{\mathrm{b}}$} & {$[0.5188 * * *]^{\mathrm{b}}$} \\
\hline Item preference & $2.9350 * * *$ & {$[3.9091 * * *]^{\mathrm{b}}$} & {$\left[3.7747^{* * * *}\right]^{\mathrm{b}}$} & Item preference & $5.2162 * * *$ & {$[5.6737 * * *]^{\mathrm{b}}$} & {$[4.2439 * * *]^{\mathrm{b}}$} \\
\hline Brand asymmetry & 0.3024 & $0.4201 * *$ & 0.5430 & Brand asymmetry & 0.0155 & 0.6193 & 0.0533 \\
\hline Size asymmetry & -0.0826 & -0.0886 & 0.0081 & Taste asymmetry & -0.0351 & $0.3031 * *$ & -0.1233 \\
\hline Sequence & & $0.4302 * *$ & -0.0883 & Type asymmetry & 0.3253 & -0.0557 & $0.3182 *$ \\
\hline Proximity (oos) & 0.8415 & $1.0628 * * *$ & 0.6424 & Sequence & -0.3019 & -0.0920 & $0.4670 * *$ \\
\hline Proximity (nt-oos) & 0.3906 & $0.8553 * * *$ & 0.4332 & Proximity (oos) & $1.9757^{* * *} *$ & $0.3508^{* * *}$ & $3.8016^{* * *}$ \\
\hline Variances & & & & Proximity (nt-oos) & 0.8160 & 0.2817 & $1.7231 * * *$ \\
\hline Last purchase & $2.0506^{* * *}$ & $1.9053^{* * *}$ & $2.2458^{* * *}$ & Variances & & & \\
\hline Brand asymmetry & 0.0636 & 0.0625 & 0.0548 & Last purchase & $3.3527 * * *$ & $0.7272 * * *$ & $2.4716^{* * *}$ \\
\hline Size asymmetry & 0.0274 & 0.0157 & 0.0205 & Brand asymmetry & $0.4054^{*}$ & 0.4309 & 0.3532 \\
\hline \multirow[t]{3}{*}{ Sequence } & $-{ }^{c}$ & 0.1138 & 0.1003 & Taste asymmetry & 0.2185 & 0.1428 & $0.4377 * *$ \\
\hline & & & & Type asymmetry & 0.1213 & $0.5004^{* * *}$ & 0.4327 \\
\hline & & & & Sequence & 0.6713 & 0.1138 & $0.9177^{* *}$ \\
\hline \multicolumn{8}{|l|}{ PANEL B } \\
\hline $\begin{array}{l}\text { Scale factor } \\
\text { Mean }\end{array}$ & [1.00] & $1.3515^{* * *}$ & $1.2771^{* * *}$ & Scale factor & {$[1.00]$} & $1.1164 * * *$ & $0.8257^{* * *}$ \\
\hline $\begin{array}{l}\text { Mean } \\
\text { Last purchase }\end{array}$ & $2.0030 * * *$ & {$\left[2.7071^{* * *}\right]^{\mathrm{b}}$} & {$\left[2.5580^{* * * *}\right]^{\mathrm{b}}$} & $\begin{array}{l}\text { Mean } \\
\text { Last purchase }\end{array}$ & $0.6907 * * *$ & {$\left[0.7711^{* * *}\right]^{\mathrm{b}}$} & {$\left[0.5703^{* * *}\right]^{\mathrm{b}}$} \\
\hline Item preference & $2.9575 * * *$ & {$[3.9971 * * *]^{b}$} & {$\left[3.7770^{* * * *}\right]^{\mathrm{b}}$} & Item preference & $5.2086^{* * *}$ & {$[5.8149 * * *]^{b}$} & {$[4.3007 * * *]^{\mathrm{b}}$} \\
\hline Brand asymmetry & 0.3087 & $0.4208 * *$ & $0.5473 *$ & Brand asymmetry & -0.0375 & 0.5809 & 0.0431 \\
\hline Size asymmetry & -0.0588 & -0.1069 & 0.0012 & Taste asymmetry & -0.0495 & $0.2955^{* *}$ & -0.1657 \\
\hline Sequence & & 0.5548 & -0.1326 & Type asymmetry & 0.3364 & -0.0454 & $0.3407 *$ \\
\hline \multirow{3}{*}{ Sequence * Disorg } & $-{ }^{c}$ & $-0.0773^{\mathrm{d}}$ & $0.0948^{\mathrm{d}}$ & Sequence & -0.2857 & -0.0992 & 0.4116 \\
\hline & & $\rightarrow$ Sign. for 4 lowest & $\rightarrow$ n.s. & Sequence * Disorg & $-0.0012^{\mathrm{d}}$ & $0.0561^{\mathrm{d}}$ & $-0.1747^{\mathrm{d}}$ \\
\hline & 0.8699 & $\begin{array}{l}\text { scores Disorg } \\
1.0798\end{array}$ & 0.7218 & & $\rightarrow$ n.s. & $\rightarrow$ n.s. & $\begin{array}{l}\rightarrow \text { Sign. for } 4 \text { lowest scores } \\
\text { Disorg }\end{array}$ \\
\hline \multirow[t]{2}{*}{ Proximity (oos) * Disorg } & $-1.0183^{\mathrm{d}}$ & $-0.4757^{\mathrm{d}}$ & $0.5987^{\mathrm{d}}$ & Proximity (oos) & 1.9353 & 1.4376 & 3.6646 \\
\hline & $\rightarrow$ Sign. for 3 lowest & $\rightarrow$ Sign. for 3 lowest & $\rightarrow$ n.s. & Proximity (oos) * Disorg & $-1.8330^{\mathrm{d}}$ & $-0.2977^{d}$ & $-0.2340^{\mathrm{d}}$ \\
\hline Proximity (nt-oos) & $\begin{array}{l}\text { scores Disorg } \\
0.3766\end{array}$ & scores Disorg & 04076 & & $\rightarrow$ Sign. for 3 lowest & $\rightarrow$ Sign. for 4 lowest scores & $\rightarrow$ Sign. for 6 lowest scores \\
\hline \multirow{2}{*}{ Proximity (nt-oos) $*$ Disorg } & $\begin{array}{l}0.3 / 66 \\
-0.4736^{\mathrm{d}}\end{array}$ & $\begin{array}{l}0.8553 \\
-0.4783^{\mathrm{d}}\end{array}$ & $\begin{array}{l}0.4076 \\
-0.0371^{\mathrm{d}}\end{array}$ & Proximity (nt-oos) & $\begin{array}{l}\text { scores Disorg } \\
0.8049\end{array}$ & $\begin{array}{l}\text { Disorg } \\
06608\end{array}$ & $\begin{array}{l}\text { Disorg } \\
1.6956\end{array}$ \\
\hline & $\rightarrow$ n.s. & $\rightarrow$ Sign. for 4 lowest & $\rightarrow$ n.s. & Proximity (nt-oos) * Disorg & $-0.2029^{\mathrm{d}}$ & $0.0297^{\mathrm{d}}$ & $-0.1398^{\mathrm{d}}$ \\
\hline $\begin{array}{l}\text { Variances } \\
\text { Last purchase }\end{array}$ & $20640 * * *$ & scores Disorg & & Voriances & $\rightarrow$ n.s. & $\rightarrow$ n.s. & $\rightarrow$ Sign. for 6 lowest scores \\
\hline & $2.0640^{* 2 \pi}$ & $1.9933^{* * *}$ & $2.2032 * * *$ & Variances & & & Disorg \\
\hline Brand asymmetry & 0.0370 & 0.1060 & 0.0005 & Last purchase & $3.2354 * * *$ & $0.8631 * *$ & $2.5170 * * *$ \\
\hline Size asymmetry & 0.0154 & 0.0028 & 0.0198 & Brand asymmetry & $0.3772 *$ & 0.3696 & 0.2335 \\
\hline Sequence & $-{ }^{c}$ & 0.1183 & 0.3209 & Taste asymmetry & 0.2420 & 0.1161 & $0.6068^{* * *}$ \\
\hline \multirow[t]{3}{*}{ Sequence * Disorg } & $-{ }^{c}$ & 0.0180 & 0.1095 & Type asymmetry & 0.1399 & $0.4570 * *$ & 0.3582 \\
\hline & & & & Sequence & 0.6713 & 0.5130 & $0.8788 * *$ \\
\hline & & & & Sequence * Disorg & 0.1481 & 0.1085 & 0.3418 \\
\hline
\end{tabular}

